\title{
Analysis of the Causes and Countermeasures of Institutional Obstacles in the Endowment Insurance Docking of Urban Workers in Beijing, Tianjin and Hebei
}

\author{
Jiwei Dou \\ School of Economics and Management Beijing Jiaotong University Beijing China \\ 15120552@bjtu.edu.cn
}

Keywords: Beijing-Tianjin-Hebei, Endowment insurance system, Cancel the minimum payment time, "Segment calculation, equity accumulation".

Abstract. Beijing, Tianjin and Hebei are not unified in social endowment insurance system. The current imperfect transfer system will restrict the labor force to flow reasonably within the capital economic circle. Based on the coordinated development, this paper analyzes the institutional differences of the endowment insurance of urban workers in Beijing and Tianjin and Hebei, analyzes the impact of the transfer system on the pension level of migrants in Beijing, Tianjin and Hebei, and further analyzes the institutional barriers Causes. Then, based on the endowment insurance system of urban workers, improve the endowment insurance system of urban workers in Beijing-Tianjin-Hebei, and adjust the transfer method and mechanism. In the end, we try to give solutions to overcome the institutional barriers through the abolition of the minimum payment period and the implementation of "sub-calculation, equity accumulation".

\section{Introduction}

At the end of February 2014, Chairman Xi Jinping delivered a speech at the Beijing-Tianjin-Hebei Collaborative Development Symposium. Since then, the Beijing-Tianjin-Hebei integration has risen to a major national strategy. Beijing-Tianjin-Hebei regional economic integration requires the free flow of production factors. The free flow of labor force is one of the cornerstones of the coordinated development of regional economy. The docking of the endowment insurance system helps to enhance the "portable" nature of the rights of the migrant workers, which is an important guarantee for the rational flow of labor factors. At the same time, the endowment insurance system docking is also an important part of Beijing-Tianjin-Hebei public service equalization[1]. Therefore, it is of great significance to promote the rational and orderly flow of labor force, ease the non-core functions of the capital and coordinate the development of Beijing-Tianjin-Hebei.

\section{Organization Institutional differences}

2.1 Not A Uniform Payment Basis. The basic endowment insurance contributions in three provinces and cities are $20 \%$ of employers, $8 \%$ of individuals, but the benchmark and the upper and lower limits of the provisions are inconsistent. Hebei is based on the total wage of workers, while Beijing and Tianjin are based on the total payment wages of workers; about the upper and lower limits, the Beijing and Tianjin are $60 \%$ and $300 \%$ of the previous year's average monthly wage of workers, Hebei is $60 \%$ and $300 \%$ of the previous year's average monthly wage of on-job workers.

2.2 Not A Uniform Distribution Method. There are two different situations: one is paid more than 15 years, the other is paid less than 15 years. When your payment time is more than 15 years, the distribution method is inconsistent. Beijing is based on the average monthly wage of the workers in the previous year, but Tianjin and Hebei are based on the average monthly wage of the on-job workers in the previous year. When your payment time is less than 15 years, the individual account fund can be once paid to the insured. In Beijing and Hebei, the insured can get some compensation, but the standard is different. However, the insured can't get the compensation in Tianjin. 


\section{The Effect of the Current Transfer Method}

Based on the actual data of the migrant people in Beijing, Tianjin and Hebei in the past, it can conclude that the transfer is not conducive to the balance of income and expenditure of Hebei Province, and will reduce the insured person's pension level from Hebei and Tianjin to Hebei Province, and improve the level of the insured person's pension from Hebei Province to Beijing and Tianjin; between Beijing and Tianjin, the migrant people are roughly flat, so their total social pension fund changes little, but it will reduce the level of the insured person's pension from Beijing to Tianjin, and improve the level of the insured person's pension from Tianjin to Beijing[2].

The reason why the transfer will have an impact on the interests of the insured, the key lies in:When the inter-provincial transfer is continued, the insured person only can transfer $12 \%$ of the pension paid by the employer during the insured period, but $8 \%$ paid by the insured is not allowed to take away; from the province of the higher wage into the province of lower wage, the level of the pension treatment will decline[3]. This is because the pension payment method does not take into account the pension that the insured has paid in other provinces and cities.

\section{The Causes of Institutional Docking Obstacles}

\subsection{The Main Problems of the Current Transfer Method}

According to the method, workers can obtain the pension that depends on whether the payment of 15 years, and it is equal to negate those who pay less than 15 years to receive the right to get the pension. Where the insured person receives the pension depends on where the payment of 10 years. If the basic endowment insurance relationship is not in the place of residence, and in each participating area the cumulative payment time is less than 10 years, then the basic endowment insurance relationship and the corresponding pension belong to the household registration.

The essence of the transfer method is the confirmation and accumulation of the endowment insurance interests, and the confirmation and implementation of the corresponding payment liability. According to the current transfer method, the pension in different areas has not been accumulated, but the years are transferred to the receiving area. This system, which separates the payment and treatment, is the real reason why some migrant people are more inclined to no longer pay the pension, compared with the transfer of endowment insurance relationship.

\subsection{The Cause of the Problem}

4.2.1 The Current Social Endowment Insurance Policy. The current transfer method requires a payment of 15 years, because China's current social endowment insurance policy provides that the insured person to receive basic pension is to pay at least 15 years, and those who pay less than 15 years don't have the basic pension. Social endowment insurance policy provides the minimum payment time is to spur the insured as much as possible to pay longer and get more, in order to achieve the minimum standard of living after the insured person retired, but in fact this purpose has not been achieved.

4.2.2 Misunderstanding the Relationship Between Individual Payment and Pension Claim. The current transfer method does not recognize or partially recognize the migrant workers' basic pension claim that they should have before transferring. For example, someone is an urban resident and later becomes an urban worker. He had paid the endowment insurance as a resident. Because this is the cost of individual payment, so it is not recognized by the urban worker's pension system, it provides that the basic pension is from the financial allocation. In fact, this is a misunderstanding about the relationship between individual payment and pension claim.

If you do not recognize the individual account fund based on personal contributions, then why does the un-flow have the basic pension claim? If the insured person's work change is the condition for the loss of the basic pension claim that has been formed, it is not justified, because the two are not causal[4]. To give a contrary example, a person who does not pay for the endowment insurance, even if he does not change the work place, he will never have the pension claim. 


\section{Countermeasures}

5.1 The Integration of Endowment Insurance System. The key point of the integration is to unify the rate and payment method, and to overcome the overburden of corporate expenses.

5.1.1 Unifying Payment Base and Its Upper and Lower Limits. The fee paid by the enterprise in Hebei Province will be changed from the total amount of the enterprise's wage to the sum of the payment wage of the workers. The upper and lower limits of the individual contribution will be changed to $60 \%$ and $300 \%$ of the average monthly wages in the province. Reduce the payment rate of enterprise in three provinces and cities, from the current $20 \%$ to $12 \%$, in order to achieve the purpose of reducing the burden of enterprise, and leave space for the development of supplementary endowment insurance system. The pension which is reduced by the reduction of the enterprise rate is shared by the central and provincial governments.

5.1.2 Improving the Current Transfer Method. In Beijing, Tianjin and Hebei, the social average wage is very different, and the basic pension should not adopt a unified base. We propose to revise the standard of Beijing in accordance with the standard of Tianjin and Hebei. In order to achieve a flexible retirement system, set the insured to receive basic pension at the age of 60 years, after the age of 60 years, you can decide when to start receiving the pension. The condition for full pension is over 60 years old and the payment time is over 40 years. If the payment time is less than 40 years, the basic pension payment rate will be reduced by 1.2 percentage points for each year; in contrast, if the payment time is more than 40 years, the basic pension payment rate will be increased by 1.2 percentage points for each year. The aim is to encourage latecomers to get more and implement the policy of delayed retirement[5]. In order to avoid the depreciation of basic pension caused by inflation, we should establish a reasonable adjustment mechanism.

5.2 Improving the Transfer Method. Through the integration of the social endowment insurance system, it is possible to link the pension claim of the insured people who are moving across the provinces and cities. However, it is necessary to fundamentally guarantee the pension claim of migrant workers and make the region reasonable to share the responsibility of the pension. Starting from the payment condition and the treatment standard, we must reform the current transfer process. 5.2.1 Canceling the Minimum Payment Time Limit. We know that the minimum payment of basic pension is set for the purpose of achieving the endowment insurance policy. The world's first annuity law is Bismarck's 《Disability and Aging Insurance Law》, it provides that the eligibility for a pension is that the receiving age is over 70 years old and the payment time is at least 30 years. The purpose of the policy is to limit the short life and short payment insured person to receive annuity, so as to alleviate the living condition of a small number of longevity workers[6].

China is now in the process of industrialization and urbanization. There are already many workers have chosen not to pay the urban worker endowment insurance, because they can't reach the minimum payment time. China will have hundreds of millions of rural residents transferred to the town. In order to achieve the aim that all people can get the pension, the abolition of the minimum payment time and the reform of the current transfer method are very necessary.

5.2.2 Segment Calculation, Equity Accumulation. But to really ensure the migrant worker's pension claim that forms in different provinces and cities, it is necessary to change the relevant provisions of the "temporary transfer method of urban worker's basic endowment insurance relationship"[7]. It is outdated that the relevant provisions of the pension payment, such as the place of treatment and the pension standard. The implementation of "Segment calculation, equity accumulation" can guarantee the insured's right under different provinces and cities. This new method is to add the pension interests of the insured under different systems, so that even if the insured has worked in several provinces, he can get what he deserves.

It is assumed that Wang has worked in three places: A, B and C, and respectively fulfills the obligation of the corresponding endowment insurance, then the monthly pension is divided into three sections, the formula can be expressed as: $\mathrm{J}_{\mathrm{A}}=\left(1+\mathrm{Z}_{\mathrm{A}}\right) / 2 * \mathrm{C}_{\mathrm{A}} * \mathrm{Q}_{\mathrm{A}} * 1 \% ; \mathrm{J}_{\mathrm{B}}=\left(1+\mathrm{Z}_{\mathrm{B}}\right) / 2 * \mathrm{C}_{\mathrm{B}} * \mathrm{Q}_{\mathrm{B}} * 1 \%$; $\mathrm{J}_{\mathrm{C}}$ $=\left(1+Z_{C}\right) / 2 * C_{C} * Q_{C} * 1 \% ; J=J_{A}+J_{B}+J_{C}$. The pension Wang should get in $A, B$ and $C$ is represented by $J_{A}, J_{B}$ and $J_{C}$. $J$ is the monthly pension. The average wage index is represented by $Z_{A}, Z_{B}$ and $Z_{C}$. 
When Wang retires, the on-the-job worker's monthly average wage is represented by $\mathrm{C}_{\mathrm{A}}, \mathrm{C}_{\mathrm{B}}$ and $\mathrm{C}_{\mathrm{C}}$. The payment time is represented by $\mathrm{Q}_{\mathrm{A}}, \mathrm{Q}_{\mathrm{B}}$ and $\mathrm{Q}_{\mathrm{C}}$. When calculating $\mathrm{J}_{\mathrm{A}}, \mathrm{J}_{\mathrm{B}}$ and $\mathrm{J}_{\mathrm{C}}$, we must first assume that Wang works here and pays the corresponding endowment insurance.

Assume Wang worked in Hangzhou for 10 years, Qingdao for 10 years, and Changsha for 10 years.In 2010,the average wage in Hangzhou, Qingdao, and Changsha is 4980 yuan, 4,000 yuan and 2480 yuan. For the convenience of calculation is now simplified to 5,000 yuan, 4,000 yuan and 2,500 yuan.

Compared the current calculation method with the new, you can get the following table:

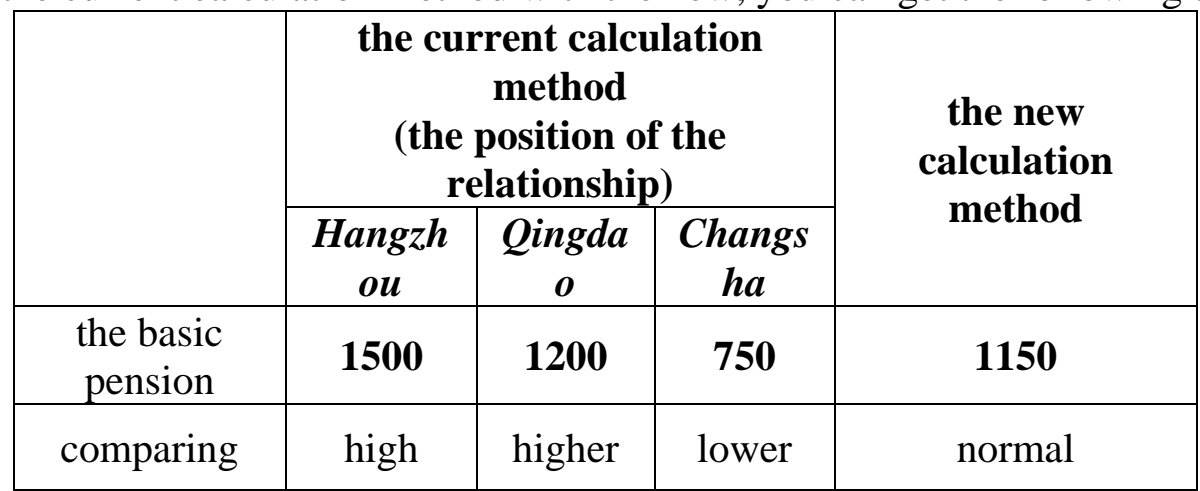

Compared with the current method, this new method will help reflect social justice, coordinate the interest of various social groups and regions, achieve national co-ordination and realize social harmony.

\section{References}

[1] K. Wen and R.J. Zhu, Beijing - Tianjin - Hebei Development Report, Beijing: Social Science Literature Publishing House, 2015.

[2] Y.F. Zhang and S.H. Chen, an Analysis of the Continuation of the Transfer of the Endowment Insurance in China, Journal of Beihua University. vol. 14, pp. 42-45.

[3] F.L. Chu, Transfer the interests to Protect Life, China Human Resources Social Security, vol.3, pp.22-23, 2010.

[4] G.L. Gai, the Cross-system Endowment Insurance Should Be Applied to the Sub-calculation, Economic world, vol.4, pp.22-24,2011.

[5] H.M. Xiao, the Inter - provincial Transfer of Endowment Insurance: Dilemma and Way, Journal of Beijing Vocational College of Labor and Social Security, vol.4, pp.11-14, 2010.

[6] K.J. Fang, EU's Legal Coordination of Social Security for Free - Flowing Workers, European Studies, vol.1, 2012.

[7] Z.T. Zhang and Z. Cheng, the Optimization Path of Basic Pension Calculation Method in China, Journal of Jianghai University, vol.3, pp.144-149, 2012. 